\title{
Neuroprotectants in the Era of Reperfusion Therapy
}

\author{
Ángel Chamorro \\ Comprehensive Stroke Center, Department of Neuroscience, Hospital Clinic and August Pi I Sunyer Biomedical Research Institute (IDIBAPS), \\ University of Barcelona, Barcelona, Spain
}

For decades, numerous pharmacological and non-pharmacological strategies have been evaluated without success to limit the consequences of the ischemic cascade, but more rarely the therapies were explored as add on remedies on individuals also receiving reperfusion therapies. It is plausible that these putative neuroprotectants never reached the ischemic brain in adequate concentrations. Currently, the concept of neuroprotection incorporates cerebral perfusion as an obligatory substrate upon which ischemic brain survival depends, and it is plausible that some of the compounds tested in previous neuroprotection trials might have resulted in more favorable results if reperfusion therapies had been co-administered. Nonetheless, pharmacological or mechanical thrombectomy are frequently powerless to fully reperfuse the ischemic brain despite achieving a high rate of recanalization. This review covers in some detail the importance of the microcirculation, and the barriers that may hamper flow reperfusion at the microcirculatory level. It describes the main mechanisms leading to microcirculatory thrombosis including oxidative/nitrosative stress and refers to recent efforts to ameliorate brain perfusion in combination with the co-administration of neuroprotectants mainly aimed at harnessing oxidative/nitrosative brain damage.

Keywords Neuroprotection; Stroke; Therapy; Reperfusion; Antioxidants; Oxidative stress
Correspondence: Ángel Chamorro Department of Neuroscience, Hospital Clinic, University of Barcelona,

Villarroel 170, Barcelona 08036, Spain Tel: +34-93-227-5414

Fax: +34-93-227-1789

E-mail: achamorro@clinic.ub.es

Received: December 13, 2017

Revised: March 14, 2018

Accepted: March 24, 2018

\section{Introduction}

A wider use of specialist stroke units, intravenous thrombolytic therapy and mechanical thrombectomy (MT) have resulted in a remarkable progress in the acute management of ischemic stroke (IS). ${ }^{1-6}$ However, IS still represents the first cause of permanent disability in adult people, the second single most frequent cause of death for people older than 60 years, the second most common cause of dementia, representing approximately $3 \%$ to $7 \%$ of the total health-care expenditure in highincome countries. ' In consequence, despite the failure of numerous previous attempts during the last decades (Figure 1), there is a pressing need to continue investigating better treatments for this devastating disease..$^{8-11}$

On theoretical grounds, neuroprotection in IS is expected to be more effective the earlier the intervention is initiated but the
Field Administration of Stroke Therapy-Magnesium (FAST-MAG) trial highlighted that treatment expeditiousness was not sufficient, as a treatment delay as short as 45 minutes after clinical onset failed to improve IS outcomes. ${ }^{12}$ Therefore, other factors need to be accounted for in the rapidly changing pathophysiology of IS, including the molecular target selected for therapeutic intervention, its time of onset and persistence throughout the ischemic process, together with the pharmacokinetics and pharmacodynamics of the putative neuroprotectant. ${ }^{13}$ As discussed below, oxidative and nitrosative stress play a major deleterious role in ischemic cell death during a large therapeutic window $_{1}{ }^{14}$ and not surprisingly this molecular target centers the attention of a number of ongoing neuroprotectant trials. Another issue of increasing interest in stroke neuroprotection is how to maximize the rate of brain reperfusion, as it represents an obligatory substrate upon which ischemic brain survival de- 


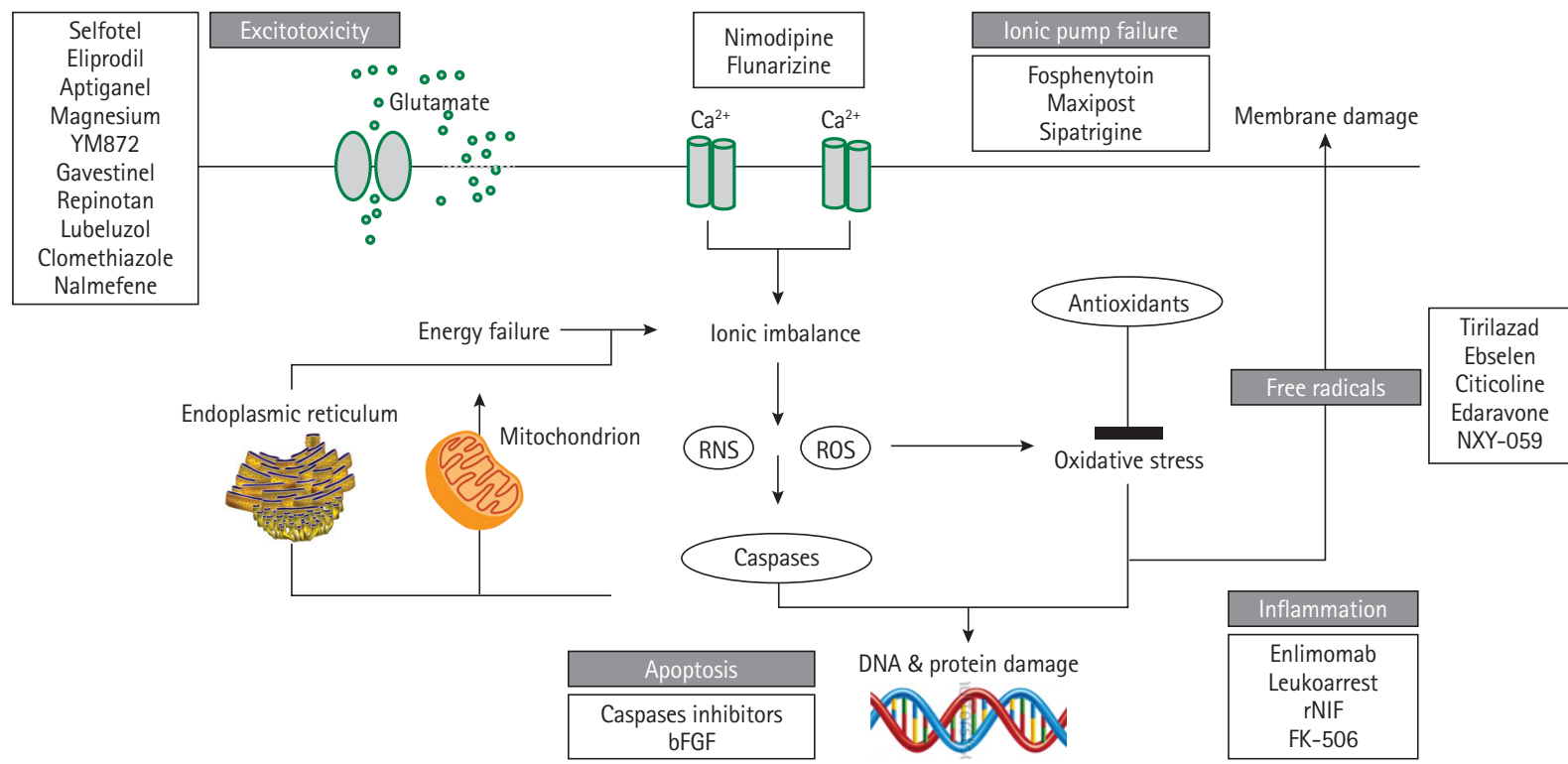

Figure 1. Neuroprotection in acute ischemic stroke. Main mechanisms of the ischemic cascade and some of the neuroprotectants asssessed in phase $2 / 3$ clinical trials without beneficial effects. RNS, reactive nitrogen species; ROS, reactive oxygen species; bFGF, basic fibroblast growth factor; rNIF, recombinant neutrophil inhibitory factor; FK-506, tacrolimus.

pends. ${ }^{15}$ Expectedly, a comprehensive approach to stroke neuroprotection would include treatment expeditiousness, a meaningful molecular target, pharmacologically fitted neuroprotectants, and strategies aimed to maximize cerebral perfusion. ${ }^{16,17}$ This review summarizes ongoing strategies aimed at attaining a more effective neuroprotection in IS based on these principles.

\section{Recanalization/complete reperfusion mismatch}

Arterial recanalization after IS is associated with a 4- to 5-fold increase in the odds of good long-term functional outcome and a 4 - to 5 -fold reduction in the odds of death. ${ }^{18}$ However, one out of four patients do not reperfuse despite complete recanalization, ${ }^{19-24}$ and one out of two develop full infarctions on regions previously hyperperfused, ${ }^{25}$ highlighting the essential role of adequate brain perfusion for the final ischemic tissue fate. In recent randomized controlled trials, ${ }_{1}^{1-6}$ less than half of patients treated with MT improved stroke outcomes regardless that three out of four had full recanalization. Arguably, the lack of clinical improvement could indicate that the recanalization occurred when a full brain infarction was established in some patients but it should be noted that only $38 \%$ of the patients obtained full reperfusion after MT, suggesting that the mismatch between complete recanalization and incomplete reperfusion explained the suboptimal efficacy of MT.

The modified thrombolysis in cerebral ischemia (mTICl) score $^{26}$ was the primary reperfusion scale used in the trials and in this scale, $\mathrm{mTICl}$ score 3 defines complete reperfusion of the target downstream territory (TDT) and $\mathrm{mTICl} 2 \mathrm{~b}$ score defines restoration of more than half of the TDT, respectively (Figure 2). ${ }^{27}$ Current guidelines recommend achieving indistinctively mTICl $2 b$ or 3 scores following MT, assuming that both scores maximize the probability of a good functional clinical outcome. ${ }^{28}$ Accordingly, successful reperfusion grouped together the patients that obtained either of these two angiographic scores in the aforementioned trials. However, some studies, ${ }^{29-31}$ but not others, ${ }^{32,33}$ showed significant outcome differences between $\mathrm{mTICl} 3$ and $2 \mathrm{~b}$ scores. Recently ${ }_{1}^{34}$ we compared the relative outcomes resulting from $\mathrm{mTICl} 2 b$ or 3 scores at the end of MT using multivariate models adjusted for Highly Effective Reperfusion Evaluated in Multiple Endovascular Stroke (HERMES) covariates..$^{35}$ In this study, patients with $\mathrm{mTICl} 3$ compared with $\mathrm{mTICl} 2 \mathrm{~b}$ had a better mRS score at 90 days (odds ratio, 2.018; 95\% confidence interval, 1.033 to 3.945), less infarct growth and smaller final infarctions, supporting a more efficient salvage of the ischemic penumbra. Therefore, mTICl 3 should always be pursued whenever technically possible, particularly in patients with salvageable tissue on brain imaging.

\section{Microvascular perfusion}

Nearly every neuron in the human brain has its own capillary and the microcirculation represents more than $96 \%$ of the entire cerebrovascular system. ${ }^{36,37}$ Short, middle, and long arteries 


\section{Angiographic results}

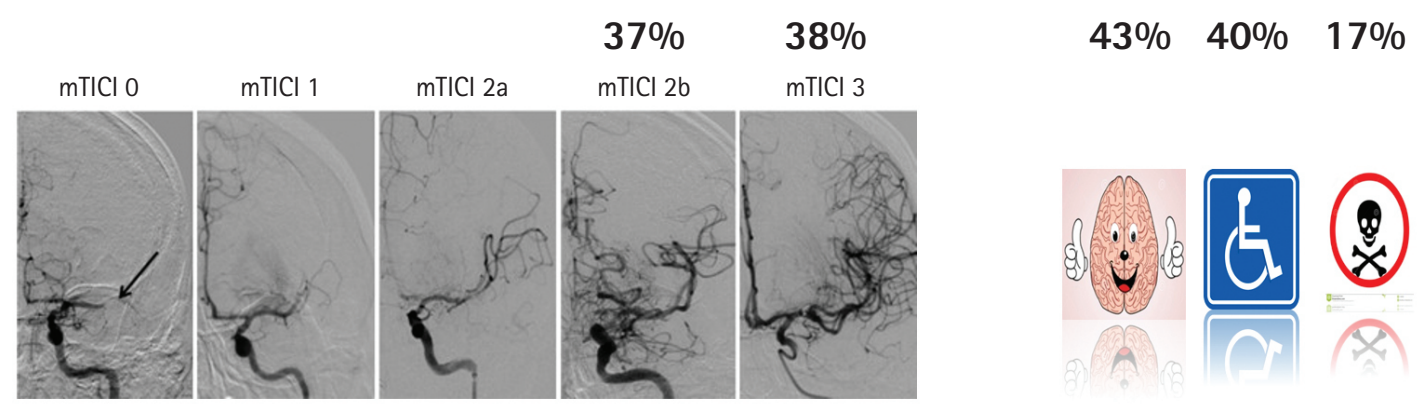

Figure 2. Main results in recent endovascular trials. Pooled percentages of the angiographic and main clinical results obtained in Randomized Trial of Revascularization with Solitaire FR Device versus Best Medical Therapy in the Treatment of Acute Stroke Due to Anterior Circulation Large Vessel Occlusion Presenting within Eight Hours of Symptom Onset (REVASCAT), Solitaire ${ }^{\text {TM }}$ with the Intention for Thrombectomy as Primary Endovascular Treatment for Acute Ischemic Stroke (SWIFT PRIME), Endovascular Treatment for Small Core and Proximal Occlusion Ischemic Stroke (ESCAPE), Extending the Time for Thrombolysis in Emergency Neurological Deficits-Intra-Arterial (EXTEND-IA), and Multicenter Randomized Clinical Trial of Endovascular Treatment for Acute Ischemic Stroke in the Netherlands (MR CLEAN). mTICl, modified thrombolysis in cerebral ischemia.

branching from the pial vessels supply the human cerebral cortex by highly interconnected capillary vessels distributed in superficial, middle, and deep vascular layers. ${ }^{38}$ Virtually all brain microvessels are constantly perfused at any time ${ }_{1}^{36}$ but changes in the microvascular structure may hamper adequate brain reperfusion following recanalization. ${ }^{39}$ Models of transient brain ischemia identified the lack of reflow at the microcirculation despite complete recanalization of proximal occlusions on albino rabbits. $^{40-42}$ It was attributed to spasm or swelling of the vessel wall, while increased blood viscosity was thought a secondary contributor. ${ }^{40} \mathrm{~A}$ rich expression of thromboplastins in the brain lent support to speculate that fibrin clots formed within the capillary bed ${ }_{1}^{40}$ while later studies also found capillary-obstructing leukocytes. ${ }^{43}$ Clogging of the perivascular space, activation of tissue factor, ${ }^{44}$ distal microembolism from a proximal thrombus, ${ }^{45,46} \mathrm{mi}-$ crovascular compression by swollen astrocyte end-feet, ${ }^{47,48}$ or platelet and neutrophil adhesion, were also associated with the no-reflow. Genetic manipulation and use of anti-inflammatory agents restored effectively the no-reflow and improved stroke outcomes in experimental animals, ${ }^{49-53}$ but pharmacologic inhibition of leukocytes, platelets, or fibrin-platelet interactions were found deleterious or futile in patients with IS..$^{54-58}$

Oxidative and nitrosative stress also participates in the noreflow as the result of a rich expression of pro-oxidant nicotinamide adenine dinucleotide phosphate (NADPH) oxidases $(\mathrm{NOX})^{59}$ in brain endothelium, vascular smooth muscle, adventitia, and capillary pericytes. ${ }^{60}$ In particular, pericytes are deemed to play a major role because pericytes apposed to central nervous system capillaries regulate the microcirculatory blood flow. ${ }^{61}$ Elegant experimental studies showed that pericytes constricted at the start of ischemia because lacking ade- nosine triphosphate was not able to pump $\mathrm{Ca}^{2+}$ out of the cell, while suppression of oxidative-nitrosative stress relieved pericyte contraction and restored microvascular patency. ${ }^{62}$

The efficacy of thrombolytic agents greatly depends on the quantity of intravascular thrombus, ${ }^{63}$ and therefore the no-reflow could be theoretically treated by manipulating the fibrinolytic system. Arguably, thrombi that form in the microvascular bed might be more susceptible to lyse than larger proximal thrombi. Based on this principle, the CHemical Optimization of Intraarterial Cerebral Embolectomy (CHOICE) trial is currently testing whether intraarterial alteplase is superior to placebo to improve the no-reflow at the end of MT, in a multicenter, double blind, placebo controlled phase 2 trial expected to terminate in late 2019.

\section{Neuroprotection of the reperfused tissue: targeting the redox state}

A major unifying thread in IS indicates that assorted molecular pathways converge following the onset of ischemia to produce damaging levels of free radicals and non-radicals such as peroxynitrite. ${ }^{64}$ Sources of high concentrations of reactive species include the mitochondria, ${ }^{65}$ the activity of cyclooxygenase enzymes ${ }_{1}^{66}$ NOX expressed by neurons, ${ }_{1}^{67}$ endothelial cells, ${ }^{68}$ and infiltrating neutrophils, and the hypoxic-dependent conversion of xanthine dehydrogenase into xanthine oxidase. Oxidative/nitrosative stress starts to rise during the early ischemic phase, followed by a much larger increment both in neurons and endothelial cells during early reperfusion. ${ }^{69}$ For this reason, there is a growing interest in the study of putative neuroprotectants that harness the redox state in the selected population of pa- 
tients treated with MT. Additionally, peroxynitrite is an especially attractive molecular target for therapeutic intervention because despite of a short half-life this compound is more toxic than other reactive species, as it crosses readily biological membranes and interacts with most critical biomolecules. ${ }^{70,71}$ Under experimental conditions, peroxynitrite is largely generated in the ischemic penumbra where it builds up for about 6 to 12 hours. $^{72}$ Once formed, peroxynitrite facilitates the demise of the penumbra by lipid peroxidation, mitochondrial damage, protein nitration and oxidation, depletion of antioxidant reserves, activation or inhibition of various signaling pathways, DNA damage, and blood-brain barrier (BBB) breakdown. ${ }^{73}$

\section{Clinical trials}

Uric acid (UA) is a potent peroxynitrite scavenger ${ }^{74,75}$ and the evaluation of its putative neuroprotectant effects is at an advanced phase of clinical development. UA is the end product of the catabolism of purines, the most abundant natural antioxidant in humans and several-fold more effective than previous antioxidant compounds tested in IS. ${ }^{76}$ Following brain ischemia there is a rapid reduction of the endogenous levels of UA that reach the nadir within 6 hours after clinical onset. ${ }^{77}$ In a rat thromboembolic model, UA conveys synergistic neuroprotection with alteplase ${ }_{1}^{78}$ and in rodents with transient or permanent ischemia UA decreases the production of reactive oxygen species (ROS), reduces infarct volume and improves outcome. ${ }^{78-81}$ UA therapy also prevents the production of superoxide, nitric oxide, nitric oxide synthase (NOS), endothelial NOS, neuronal NOS, and interleukin-18 in the ischemic arterial wall, and protein nitrosylation in the brain despite a poor BBB permeability, ${ }^{81}$ suggesting UA mediated neuroprotection mainly derives from the cerebral vasculature. Recently, the Efficacy Study of Combined Treatment With Uric Acid and r-tPA in Acute Ischemic Stroke (URICO-ICTUS) trial confirmed in 421 patients with IS the safety of UA therapy in combination with alteplase, and a significant reduction in the risk of early ischemic worsening (Figure 3). ${ }^{82}$ Whilst the trial was unable to demonstrate a significant benefit in the whole study population, it significantly achieved the primary outcome of the trial in predefined subgroup analyses, including in women ${ }_{1}^{83}$ patients of either sex having stress hyperglycemia ${ }_{1}^{84}$ and patients that received MT as part of the initial reperfusion therapy. ${ }^{85}$ In the latter group, UA therapy showed a 19\% absolute increase in the proportion of good outcome compared with placebo despite similar rates of complete reperfusion at the end of MT. The Uric acid in Reperfusion Injury Control (URIC) trial has been recently planned to validate the URICO-ICTUS results in a larger population of patients treated with MT.

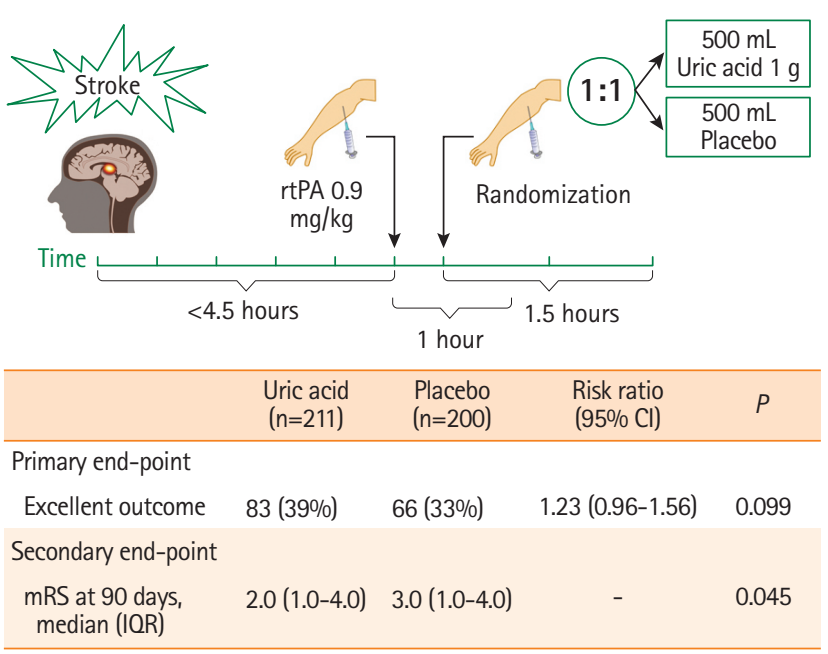

Figure 3. Study flow and main outcomes in Efficacy Study of Combined Treatment With Uric Acid and r-tPA in Acute Ischemic Stroke (URICO-ICTUS) trial 3. All the patients received alteplase within 4.5 hours after symptoms onset and were randomized 1:1 to a 90 minutes intravenous infusion of uric acid or placebo. The primary outcome-rate of patients with a modified Rankin Scale (mRS) score 0 to 1, or 2 if this was the premorbid functional status-showed a non-significant statistical trend. Main secondary outcomes, including the median mRS ( $P=0.05)$ and the mRS shift (odds ratio, 1.40; 95\% confidence interval $[\mathrm{Cl}], 0.99$ to $1.98 ; P=0.05$ ) were statistically significant. rtPA, recombinant tissue plasminogen activator; IQR, interquartile range.

The ongoing Safety and Optimal Neuroprotection of neu2000 in Ischemic Stroke With Endovascular reCanalization (SONIC) trial (NCT02831088) aims to provide proof-of-concept for use of Neu2000 as an adjunct neuroprotective agent together with state-of-the art endovascular therapy (EVT) in patients with IS. Neu2000 (a derivative of sulfasalazine) is a novel, multitarget neuroprotectant that combines modest, subtype-selective (NR2B) blockade of N-methyl-D-aspartate (NMDA) receptors with potent scavenging of ROS. ${ }^{86,87}$ It has been suggested that the prior failure of more potent, and subtype unselective NMDA antagonist drugs in stroke trials may be partly due to excessive reduction of intracellular free calcium levels and consequent enhancement of ischemic neuronal apoptosis. ${ }^{88}$ Neu2000 seeks to blunt acute excitotoxicity without risking this downside, and then to additionally target downstream free-radical damage, prominently triggered by vascular reperfusion. The neuroprotective potential of Neu2000 has been demonstrated in preclinical animal stroke models with a favorable efficacy and therapeutic window (administration in delayed time window) profile. 88,89

Plasma glucose is another important stressor in experimental models of focal cerebral ischemia/reperfusion which may contribute to the worsening the fate of stroke. ${ }^{90,91}$ Unlike originally incriminated ${ }_{1}^{92}$ extracellular lactate accumulation is not a crucial determinant of brain injury in experimental hyperglycemia, ${ }_{13}^{93}$ for 
prevention of tissue acidosis does not avoid brain tissue damage under hyperglycemic conditions. ${ }^{94}$ Rather, oxidative stress and inflammatory mechanisms are increasingly involved in hyperglycemia-induced endothelial injury in transient ischemia ${ }_{1}^{95}$ while antioxidants have shown experimentally to attenuate this damage. ${ }^{96}$ Inactivation of the glucose-dependent nicotinamide adenine dinucleotide phosphate oxidase enzyme blocks neuronal ROS production and negates the deleterious effects of hyperglycemia. ${ }^{97}$ As discussed above, in URICO-ICTUS, UA therapy was more effective in patients with stress hyperglycemia than in normoglycemic patients at stroke onset, suggesting that a greater availability of glucose increased the formation of free radicals in the ischemic penumbra ${ }^{98}$ Currently, the Intensive Insulin Therapy With Tight Glycemic Control to Improve Outcomes After Endovascular Therapy for Acute Ischemic Stroke trial (NCT02054429) is assessing the safety and efficacy of lowering glucose (blood sugar), in addition to MT, to improve 90-day functional and neurological outcomes in comparison to standard glycemic care in 100 patients with IS. The study will involve treatment of 100 (50 intensive insulin therapy and 50 standard glycemic control) non-diabetic patients presenting within 8 hours of acute IS who have undergone EVT.

\section{Preclinical studies}

Other compounds with redox based properties have shown neuroprotective effects in experimental models of brain ischemia but have not reached yet a phase of clinical testing at the bedside. Amongst these compounds, 3, 4-dihydro-6-hydroxy7-methoxy-2,2-dimethyl-1(2H)-benzopyran (CR-6) is a syn-

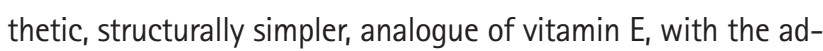
ditional capacity to scavenge nitrogen-reactive species, that has shown neuroprotective effects in brain ischemic rats. ${ }^{99} \mathrm{In}$ terestingly, CR-6 was only effective in animals that developed hyperemia at reperfusion, highlighting the relevance of reperfusion for redox based neuroprotection. ${ }^{99}$

Another treatment option supports directly targeting the right enzymatic source of ROS rather than applying non-specific antioxidants after radicals have already been generated. ${ }^{100}$ It has also been proposed a more targeted supply of antioxidants to key subcellular locations, for example the mitochondria. ${ }^{101} \mathrm{~A}$ most attractive candidate is the NOX family, the only known enzymes solely dedicated to ROS production. NOX are multicomponent protein complexes containing a catalytic subunit that transfers electrons from NADPH to oxygen, thereby forming ROS. There are seven isoforms with different tissue distribution and whose components are separated between the cytosol and the plasma membrane..$^{102}$ Under basal conditions, these components are kept apart rendering the enzyme inactive, but becoming activated at the onset of reperfusion. ${ }^{59}$ NOX 4 is the most widely distributed NOX isoform in the vasculature and its expression is higher in cerebral arteries compared with peripheral blood vessels. ${ }^{103}$ After an ischemic insult, NOX4 is upregulated in neuronal cells and brain microvascular endothelial cells, ${ }_{1}^{104}$ while NOX2 is synthesized by microglial cells and recruited phagocytes. ${ }^{105}$ Controversies remain whether NOX2, ${ }^{106}$ or NOX $4^{107}$ plays the most relevant role in stroke pathophysiology, although deletion of both NOX $2{ }^{108}$ and NOX $4{ }^{109}$ have been associated with reduction in infarct size, while overexpression of NOX4 was associated with larger infarcts. ${ }^{110}$

Compounds with a low specificity to inhibit NOX have also been investigated in experimental models of cerebral ischemia/ reperfusion injury, including diphenylene iodonium, ${ }^{111}$ the serine protease inhibitor 4-(2-aminoethyl) benzenesulfonyl fluoride, ${ }^{112}$ and 3-hydroxy-3-methyl-glutaryl reductase inhibitors (statins). ${ }^{113}$ L-arginine is a NOS substrate and precursor to nitric oxide, as well as an enhancer of cerebral blood flow. ${ }^{114}$ In 10 experimental studies of the effects of L-arginine on behavior and/or infarct volume the results were heterogeneous and inconclusive. ${ }^{115,116}$

Another approach is to boost the activity or preventing the inhibition of intrinsic antioxidant defenses, including the recently discovered master regulators of antioxidant defenses nuclear factor-erythroid 2-related factor 2 (Nrf2) or peroxisome proliferator-activated receptor- $\gamma$ coactivator $1 a^{117}$ Recently, Nrf2 has shown cytoprotective mechanisms in the retina in response to ischemia-reperfusion injury and pharmacologic induction of Nrf2 has been posited as a new therapeutic strategy for retinal ischemia-reperfusion. ${ }^{117}$

The toxicity of peroxynitrite may also be prevented indirectly by strategies that block nitric oxide or superoxide generation, or by using direct approaches including peroxynitrite or peroxynitrite-derived radical scavengers, and peroxynitrite decomposition catalysts. ${ }^{118}$ In addition to the effects of UA discussed previously, other indirect inhibitors of peroxynitrite include $\mathrm{N}$-tertbutyL-a-phenylnitrone (PBN), the NOS inhibitor $\mathrm{N} \omega$ nitro-L-arginine (L-NA), and the BBB-impermeable NOS inhibitor L-N5-(1-iminoethyl)-ornithine (L-NIO). These three agents have shown to prevent pericyte constriction, restore the patency of capillaries, and improve tissue recovery in brain ischemic mice. ${ }^{62,119}$ Interestingly, a similar degree of neuroprotection and inhibition of 3-nitrotyrosine formation was found with the BBB-impermeable L-NIO, as compared to BBB-permeable L-NA and $\mathrm{PBN}_{1}{ }^{62}$ emphasizing that the vasculature is a major source of radicals during reperfusion and suggesting that vascular-bed strategies can result in an effective neuroprotection.

Peroxiredoxins (Prxs) belong to a ubiquitous family of peroxidases that have been shown to readily and catalytically reduce 
peroxynitrite to nitrite through the reaction of the peroxidatic cysteine. There is emerging evidence that the antioxidant Prxs become inactivated during an ischemic episode, ${ }^{120}$ and Prxs have also been shown to be protective in several models of ischemia in vitro and in vivo through overexpression studies. ${ }^{121}$

Synthetic molecules that react directly and catalytically decompose peroxynitrite include metalloporphyrins of iron and manganese. Peroxynitrite decomposition catalysts such as 5,10,15,20-tetrakis(N-methyl-4'-pyridyl) porphyrinato iron III (5+) (FeTMPyP) and 5,10,15,20-tetrakis(4'-sulphonatophenyl) porphyrinato iron III (3-) (FeTPPS) can reduce infarction size, brain edema, and neurological deficits when administered at 6-hour after experimental ischemia, ${ }^{122}$ and improve vascular dysfunction in mild hyperglycemic ischemic rats. ${ }^{123}$ The catalyzed reaction is a net isomerization of peroxynitrite to nitrate. The efficacy of some of the manganese-based compounds, primarily MnTE-2-PyP (5+), have been tested in vivo and have shown to exert marked neuroprotective effects against focal ischemic insults. ${ }^{124}$ The fact that the compound remained effective even when it was given up to 6 hours after ischemia implicates the role of peroxynitrite in the delayed ischemic death processes. A related compound, $\mathrm{Mn}$ (III) tetrakis ( $\mathrm{N}-\mathrm{N}^{\prime}$-diethylimidazolium-2yl) porphyrin (AEOL-10150) has demonstrated efficacy in preclinical models of stroke in rats and mice although the greater effects were observed following intracerebroventricular administration, although more modest effects were seen after intravenous injection, which may limit its clinical use. ${ }^{124}$

\section{Conclusions}

For many years the field of neuroprotection in IS has yielded a long record of frustrating clinical results but also great advances in our understanding of the mechanisms unleashed during the ischemic cascade including the major role of oxidative and nitrosative stress within the brain parenchyma and in the microcirculation. Most previous neuroprotectant trials gave limited emphasis to the importance of full reperfusion to salvage the ischemic penumbra, casting doubts at what concentration the putative neuroprotectant did reach the ischemic neurovascular unit. The advent of MT offers an excellent opportunity to reverse this situation and opens a new scenario where combined strategies might maximize the arrival of the neuroprotectants to the tissue at risk and also the reperfusion of the microcirculation. Hopefully, the new strategies which are currently undergoing might contribute to declare soon that the inability to effectively protect the ischemic brain at the bed side is a hardship of the past.

\section{Disclosure}

Ángel Chamorro is inventor of the patent "Pharmaceutical composition for neuroprotective treatment in patients with ictus comprising citicoline and uric acid."

\section{Acknowledgments}

Supported by FIS PI15/00430, co-financed by the ISCIII-Subdirección General de Evaluación and Fondo Europeo de Desarrollo Regional (FEDER) and "CERCA Programme/Generalitat de Catalunya."

\section{References}

1. Jovin TG, Chamorro A, Cobo E, de Miquel MA, Molina CA, Rovira $A$, et al. Thrombectomy within 8 hours after symptom onset in ischemic stroke. N Eng/ J Med 2015;372:2296-2306.

2. Saver JL, Goyal M, Bonafe A, Diener HC, Levy El, Pereira VM, et al. Stent-retriever thrombectomy after intravenous t-PA vs. t-PA alone in stroke. N Engl J Med 2015;372:2285-2295.

3. Goyal M, Demchuk AM, Menon BK, Eesa M, Rempel JL, Thornton J, et al. Randomized assessment of rapid endovascular treatment of ischemic stroke. N Engl J Med 2015;372:1019-1030.

4. Campbell BC, Mitchell PJ, Kleinig TJ, Dewey HM, Churilov L, Yassi $\mathrm{N}$, et al. Endovascular therapy for ischemic stroke with perfusion-imaging selection. N Engl J Med 2015;372:10091018.

5. Berkhemer OA, Fransen PS, Beumer D, van den Berg LA, Lingsma $\mathrm{HF}_{1}$ Yoo $\mathrm{A}$, et al. A randomized trial of intraarterial treatment for acute ischemic stroke. N Eng/ J Med 2015;372:11-20.

6. Nogueira RG, Jadhav AP, Haussen DC, Bonafe A, Budzik RF, Bhuva $P$, et al. Thrombectomy 6 to 24 hours after stroke with a mismatch between deficit and infarct. N Engl J Med 2018; 378:11-21.

7. Feigin VL, Forouzanfar $M H$, Krishnamurthi $R$, Mensah GA, Connor $\mathrm{M}$, Bennett DA, et al. Global and regional burden of stroke during 1990-2010: findings from the Global Burden of Disease Study 2010. Lancet 2014;383:245-254.

8. Gladstone DJ, Black SE, Hakim AM; Heart and Stroke Foundation of Ontario Centre of Excellence in Stroke Recovery. Toward wisdom from failure: lessons from neuroprotective stroke trials and new therapeutic directions. Stroke 2002;33: 2123-2136.

9. Cheng YD, Al-Khoury L, Zivin JA. Neuroprotection for ischemic stroke: two decades of success and failure. NeuroRx 2004; $1: 36-45$

10. Savitz SI, Schäbitz WR. A critique of SAINT II: wishful think- 
ing, dashed hopes, and the future of neuroprotection for acute stroke. Stroke 2008;39:1389-1391.

11. Chamorro Á, Dirnagl U, Urra X, Planas AM. Neuroprotection in acute stroke: targeting excitotoxicity, oxidative and nitrosative stress, and inflammation. Lancet Neurol 2016;15:869-881.

12. Saver JL, Starkman S, Eckstein M, Stratton SJ, Pratt FD, Hamilton $\mathrm{S}$, et al. Prehospital use of magnesium sulfate as neuroprotection in acute stroke. N Engl J Med 2015;372:528-536.

13. Feuerstein GZ, Zaleska MM, Krams M, Wang X, Day M, Rut-

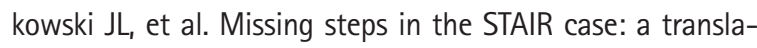
tional medicine perspective on the development of NXY-059 for treatment of acute ischemic stroke. J Cereb Blood Flow Metab 2008;28:217-219.

14. Lipton P. Ischemic cell death in brain neurons. Physiol Rev 1999;79:1431-1568.

15. Tsai JP, Albers GW. Reperfusion versus recanalization: the winner is.... Stroke 2015;46:1433-1434.

16. Amaro S, Chamorro Á. Translational stroke research of the combination of thrombolysis and antioxidant therapy. Stroke 2011;42:1495-1499.

17. Savitz SI, Baron JC, Yenari MA, Sanossian N, Fisher M. Reconsidering neuroprotection in the reperfusion era. Stroke 2017;48:3413-3419.

18. Rha $J H$, Saver JL. The impact of recanalization on ischemic stroke outcome: a meta-analysis. Stroke 2007;38:967-973.

19. Warach S, Latour LL. Evidence of reperfusion injury, exacerbated by thrombolytic therapy, in human focal brain ischemia using a novel imaging marker of early blood-brain barrier disruption. Stroke 2004;35(11 Suppl 1):2659-2661.

20. Soares BP, Tong E, Hom J, Cheng SC, Bredno J, Boussel L, et al. Reperfusion is a more accurate predictor of follow-up infarct volume than recanalization: a proof of concept using CT in acute ischemic stroke patients. Stroke 2010;41:e34-e40.

21. Baird AE, Donnan GA, Austin MC, Fitt GJ, Davis SM, McKay WJ. Reperfusion after thrombolytic therapy in ischemic stroke measured by single-photon emission computed tomography. Stroke 1994;25:79-85.

22. Khatri P, Neff J, Broderick JP, Khoury JC, Carrozzella J, Tomsick $T$, et al. Revascularization end points in stroke interventional trials: recanalization versus reperfusion in IMS-I. Stroke 2005;36:2400-2403.

23. Albers GW, Thijs VN, Wechsler L, Kemp S, Schlaug G, Ska-

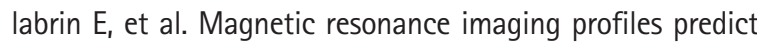
clinical response to early reperfusion: the diffusion and perfusion imaging evaluation for understanding stroke evolution (DEFUSE) study. Ann Neurol 2006;60:508-517.

24. De Silva DA, Fink JN, Christensen $S$, Ebinger M, Bladin C, Levi $C R$, et al. Assessing reperfusion and recanalization as mark- ers of clinical outcomes after intravenous thrombolysis in the echoplanar imaging thrombolytic evaluation trial (EPITHET). Stroke 2009;40:2872-2874.

25. Kidwell CS, Saver JL, Mattiello J, Starkman S, Vinuela F, Duckwiler $\mathrm{G}$, et al. Diffusion-perfusion MRI characterization of post-recanalization hyperperfusion in humans. Neurology 2001;57:2015-2021.

26. Tomsick T, Broderick J, Carrozella J, Khatri P, Hill M, Palesch Y, et al. Revascularization results in the interventional management of stroke II trial. AJNR Am J Neuroradio/ 2008;29:582587.

27. Khatri $P$, Hill MD, Palesch YY, Spilker J, Jauch EC, Carrozzella $J A$, et al. Methodology of the interventional management of stroke III trial. Int J Stroke 2008;3:130-137.

28. Powers WJ, Derdeyn CP, Biller J, Coffey CS, Hoh BL, Jauch EC, et al. 2015 American Heart Association/American Stroke Association focused update of the 2013 guidelines for the early management of patients with acute ischemic stroke regarding endovascular treatment: a guideline for healthcare professionals from the American Heart Association/American Stroke Association. Stroke 2015;46:3020-3035.

29. Kleine JF, Wunderlich S, Zimmer C, Kaesmacher J. Time to redefine success? $\mathrm{TICl} 3$ versus $\mathrm{TICl} 2 \mathrm{~b}$ recanalization in middle cerebral artery occlusion treated with thrombectomy. J Neurointerv Surg 2017;9:117-121.

30. Almekhlafi MA, Mishra S, Desai JA, Nambiar V, Volny O, Goel $A$, et al. Not all "successful" angiographic reperfusion patients are an equal validation of a modified $\mathrm{TICl}$ scoring system. Interv Neuroradiol 2014;20:21-27.

31. Dargazanli C, Consoli A, Barral M, Labreuche J, Redjem H, Ciccio $\mathrm{G}$, et al. Impact of modified $\mathrm{TICl} 3$ versus modified $\mathrm{TICl}$ $2 \mathrm{~b}$ reperfusion score to predict good outcome following endovascular therapy. AJNR Am J Neuroradiol 2017;38:90-96.

32. Yoo AJ, Simonsen $C Z$, Prabhakaran $S$, Chaudhry ZA, Issa MA,

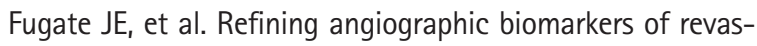
cularization: improving outcome prediction after intra-arterial therapy. Stroke 2013;44:2509-2512.

33. Linfante I, Starosciak AK, Walker GR, Dabus G, Castonguay AC, Gupta $R$, et al. Predictors of poor outcome despite recanalization: a multiple regression analysis of the NASA registry. J Neurointerv Surg 2016;8:224-229.

34. Chamorro Á, Blasco J, López A, Amaro S, Román LS, Llull L, et al. Complete reperfusion is required for maximal benefits of mechanical thrombectomy in stroke patients. Sci Rep 2017;7:11636.

35. Saver JL, Goyal M, van der Lugt A, Menon BK, Majoie CB, Dippel DW, et al. Time to treatment with endovascular thrombectomy and outcomes from ischemic stroke: a meta- 
analysis. JAMA 2016;316:1279-1288.

36. Zlokovic BV. Neurovascular mechanisms of Alzheimer's neurodegeneration. Trends Neurosci 2005;28:202-208.

37. Begley DJ, Brightman MW. Structural and functional aspects of the blood-brain barrier. Prog Drug Res 2003;61:39-78.

38. Reina-De La Torre F, Rodriguez-Baeza A, Sahuquillo-Barris J. Morphological characteristics and distribution pattern of the arterial vessels in human cerebral cortex: a scanning electron microscope study. Anat Rec 1998;251:87-96.

39. Dalkara T, Arsava EM. Can restoring incomplete microcirculatory reperfusion improve stroke outcome after thrombolysis? J Cereb Blood Flow Metab 2012;32:2091-2099.

40. Ames A 3rd, Wright RL, Kowada M, Thurston JM, Majno G. Cerebral ischemia. II. The no-reflow phenomenon. Am J Pathol 1968;52:437-453.

41. Crowell RM, Olsson Y. Impaired microvascular filling after focal cerebral ischemia in the monkey. Modification by treatment. Neurology 1972;22:500-504.

42. Little JR, Kerr FWL, Sundt TM. Microcirculatory obstruction in focal cerebral ischemia: an electron microscopic investigation in monkeys. Stroke 1976;7:25-30.

43. del Zoppo GJ, Schmid-Schönbein GW, Mori E, Copeland BR, Chang CM. Polymorphonuclear leukocytes occlude capillaries following middle cerebral artery occlusion and reperfusion in baboons. Stroke 1991;22:1276-1283.

44. Okada Y, Copeland BR, Fitridge R, Koziol JA, del Zoppo GJ. Fibrin contributes to microvascular obstructions and parenchymal changes during early focal cerebral ischemia and reperfusion. Stroke 1994;25:1847-1853.

45. Busch $E$, Krüger $K$, Allegrini $P R$, Kerskens CM, Gyngell $M L$, Hoehn-Berlage $M$, et al. Reperfusion after thrombolytic therapy of embolic stroke in the rat: magnetic resonance and biochemical imaging. J Cereb Blood Flow Metab 1998;18:407-418.

46. Heye N, Cervos-Navarro J. Microthromboemboli in acute infarcts: analysis of 40 autopsy cases. Stroke 1996;27:431-434.

47. Ito U, Hakamata $Y$, Kawakami E, Oyanagi K. Temporary [corrected] cerebral ischemia results in swollen astrocytic endfeet that compress microvessels and lead to delayed [corrected] focal cortical infarction. J Cereb Blood Flow Metab 2011;31:328-338.

48. Theilen $H_{1}$ Schröck $H$, Kuschinsky W. Gross persistence of capillary plasma perfusion after middle cerebral artery occlusion in the rat brain. J Cereb Blood Flow Metab 1994;14:1055-1061.

49. Mori E, del Zoppo GJ, Chambers JD, Copeland BR, Arfors KE. Inhibition of polymorphonuclear leukocyte adherence suppresses no-reflow after focal cerebral ischemia in baboons. Stroke 1992;23:712-718.

50. Choudhri TF, Hoh BL, Zerwes HG, Prestigiacomo CJ, Kim SC
Connolly ES Jr, et al. Reduced microvascular thrombosis and improved outcome in acute murine stroke by inhibiting GP Ilb/Illa receptor-mediated platelet aggregation. J Clin Invest 1998;102:1301-1310.

51. Abumiya $T$, Fitridge $R$, Mazur C, Copeland BR, Koziol JA, Tschopp JF, et al. Integrin alpha(Ilb)beta(3) inhibitor preserves microvascular patency in experimental acute focal cerebral ischemia. Stroke 2000;31:1402-1409.

52. Belayev L, Pinard E, Nallet $H$, Seylaz J, Liu $Y$, Riyamongkol $P$, et al. Albumin therapy of transient focal cerebral ischemia: in vivo analysis of dynamic microvascular responses. Stroke 2002;33:1077-1084.

53. Ishikawa M, Vowinkel T, Stokes KY, Arumugam TV, Yilmaz G, Nanda $A$, et al. CD40/CD40 ligand signaling in mouse cerebral microvasculature after focal ischemia/reperfusion. Circulation 2005;111:1690-1696.

54. del Zoppo GJ. Acute anti-inflammatory approaches to ischemic stroke. Ann N Y Acad Sci 2010;1207:143-148.

55. Adams HP Jr, Effron MB, Torner J, Dávalos A, Frayne J, Teal P, et al. Emergency administration of abciximab for treatment of patients with acute ischemic stroke: results of an international phase III trial: Abciximab in Emergency Treatment of Stroke Trial (AbESTT-II). Stroke 2008;39:87-99.

56. Enlimomab Acute Stroke Trial Investigators. Use of antiICAM-1 therapy in ischemic stroke: results of the Enlimomab Acute Stroke Trial. Neurology 2001;57:1428-1434.

57. Krams M, Lees KR, Hacke W, Grieve AP, Orgogozo JM, Ford $\mathrm{GA}$, et al. Acute stroke therapy by inhibition of neutrophils (ASTIN): an adaptive dose-response study of UK-279,276 in acute ischemic stroke. Stroke 2003;34:2543-2548.

58. Ginsberg MD, Palesch YY, Hill MD, Martin RH, Moy CS, Barsan $W G$, et al. High-dose albumin treatment for acute ischaemic stroke (ALIAS) part 2: a randomised, double-blind, phase 3, placebo-controlled trial. Lancet Neuro/ 2013;12:1049-1058.

59. Miller AA, Drummond GR, Schmidt HH, Sobey CG. NADPH oxidase activity and function are profoundly greater in cerebral versus systemic arteries. Circ Res 2005;97:1055-1062.

60. Kuroda J, Ago T, Nishimura A, Nakamura K, Matsuo R, Wakisaka $Y$, et al. Nox4 is a major source of superoxide production in human brain pericytes. J Vasc Res 2014;51:429-438.

61. Hall CN, Reynell C, Gesslein B, Hamilton NB, Mishra A, Sutherland BA, et al. Capillary pericytes regulate cerebral blood flow in health and disease. Nature 2014;508:55-60.

62. Yemisci M, Gursoy-Ozdemir Y, Vural A, Can A, Topalkara K, Dalkara T. Pericyte contraction induced by oxidative-nitrative stress impairs capillary reflow despite successful opening of an occluded cerebral artery. Nat Med 2009;15:1031-1037.

63. Puetz V, Dzialowski I, Hill MD, Subramaniam S, Sylaja PN, 
Krol A, et al. Intracranial thrombus extent predicts clinical outcome, final infarct size and hemorrhagic transformation in ischemic stroke: the clot burden score. Int J Stroke 2008;3: 230-236.

64. Halliwell B, Gutteridge JMC. Oxygen radicals and the nervous system. Trends Neurosci 1985;8:22-26.

65. Sims NR, Anderson MF. Mitochondrial contributions to tissue damage in stroke. Neurochem Int 2002;40:511-526.

66. Kawano T, Anrather J, Zhou P, Park L, Wang G, Frys KA, et al. Prostaglandin E2 EP1 receptors: downstream effectors of COX-2 neurotoxicity. Nat Med 2006;12:225-229.

67. Vallet $P$, Charnay $Y$, Steger $K$, Ogier-Denis $E_{1}$ Kovari $E_{1}$ Her-

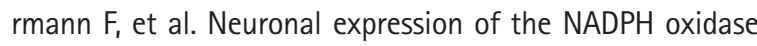
NOX4, and its regulation in mouse experimental brain ischemia. Neuroscience 2005;132:233-238.

68. Ago T, Kitazono T, Kuroda J, Kumai Y, Kamouchi M, Ooboshi $\mathrm{H}$, et al. $\mathrm{NAD}(\mathrm{P}) \mathrm{H}$ oxidases in rat basilar arterial endothelial cells. Stroke 2005;36:1040-1046.

69. Kim GW, Kondo T, Noshita N, Chan PH. Manganese superoxide dismutase deficiency exacerbates cerebral infarction after focal cerebral ischemia/reperfusion in mice: implications for the production and role of superoxide radicals. Stroke 2002;33:809-815.

70. Pryor WA, Squadrito GL. The chemistry of peroxynitrite: a product from the reaction of nitric oxide with superoxide. Am J Physiol 1995;268(5 Pt 1):L699-L722.

71. Beckman JS. Oxidative damage and tyrosine nitration from peroxynitrite. Chem Res Toxicol 1996;9:836-844.

72. Fabian RH, DeWitt DS, Kent TA. In vivo detection of superoxide anion production by the brain using a cytochrome c electrode. J Cereb Blood Flow Metab 1995;15:242-247.

73. Becker BF. Towards the physiological function of uric acid. Free Radic Biol Med 1993;14:615-631.

74. Squadrito $G L$, Cueto $R$, Splenser $A E$, Valavanidis $A$, Zhang $H$, Uppu RM, et al. Reaction of uric acid with peroxynitrite and implications for the mechanism of neuroprotection by uric acid. Arch Biochem Biophys 2000;376:333-337.

75. Maples KR, Ma F, Zhang YK. Comparison of the radical trapping ability of PBN, S-PPBN and NXY-059. Free Radic Res 2001;34:417-426.

76. Amaro S, Soy D, Obach V, Cervera A, Planas AM, Chamorro A. A pilot study of dual treatment with recombinant tissue plasminogen activator and uric acid in acute ischemic stroke. Stroke 2007;38:2173-2175.

77. Romanos E, Planas AM, Amaro S, Chamorro A. Uric acid reduces brain damage and improves the benefits of rt-PA in a rat model of thromboembolic stroke. J Cereb Blood Flow Metab 2007;27:14-20.
78. Haberman F, Tang SC, Arumugam TV, Hyun DH, Yu QS, Cutler $R G$, et al. Soluble neuroprotective antioxidant uric acid analogs ameliorate ischemic brain injury in mice. Neuromolecular Med 2007;9:315-323.

79. Ma YH, Su N, Chao XD, Zhang YQ, Zhang L, Han F, et al. Thioredoxin-1 attenuates post-ischemic neuronal apoptosis via reducing oxidative/nitrative stress. Neurochem Int 2012;60: 475-483.

80. Onetti $Y$, Dantas AP, Pérez B, Cugota $R$, Chamorro A, Planas $A M$, et al. Middle cerebral artery remodeling following transient brain ischemia is linked to early postischemic hyperemia: a target of uric acid treatment. Am J Physiol Heart Circ Physiol 2015;308:H862-H874.

81. Chamorro A, Amaro S, Castellanos M, Segura T, Arenillas J, Martí-Fábregas J, et al. Safety and efficacy of uric acid in patients with acute stroke (URICO-ICTUS): a randomised, double-blind phase 2b/3 trial. Lancet Neurol 2014;13:453-460.

82. Llull $L$, Laredo $C$, Renú $A$, Pérez $B$, Vila $E$, Obach $V$, et al. Uric acid therapy improves clinical outcome in women with acute ischemic stroke. Stroke 2015;46:2162-2167.

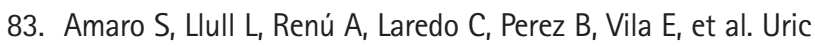
acid improves glucose-driven oxidative stress in human ischemic stroke. Ann Neurol 2015;77:775-783.

84. Chamorro Á, Amaro S, Castellanos M, Gomis M, Urra X, Blasco J, et al. Uric acid therapy improves the outcomes of stroke patients treated with intravenous tissue plasminogen activator and mechanical thrombectomy. Int J Stroke 2017; 12:377-382.

85. Gwag BJ, Lee YA, Ko SY, Lee MJ, Im DS, Yun BS, et al. Marked prevention of ischemic brain injury by Neu2000, an NMDA antagonist and antioxidant derived from aspirin and sulfasalazine. J Cereb Blood Flow Metab 2007;27:1142-1151.

86. Cho SI, Park UJ, Chung JM, Gwag BJ. Neu2000, an NR2B-selective, moderate NMDA receptor antagonist and potent spin trapping molecule for stroke. Drug News Perspect 2010;23: 549-556.

87. Lee JM, Zipfel GJ, Choi DW. The changing landscape of ischaemic brain injury mechanisms. Nature 1999;399(6738 Suppl):A7-A14.

88. Park UJ, Lee YA, Won SM, Lee JH, Kang SH, Springer JE, et al. Blood-derived iron mediates free radical production and neuronal death in the hippocampal CA1 area following transient forebrain ischemia in rat. Acta Neuropathol 2011;121: 459-473.

89. Pulsinelli WA, Waldman S, Rawlinson D, Plum F. Moderate hyperglycemia augments ischemic brain damage: a neuropathologic study in the rat. Neurology 1982;32:1239-1246.

90. Yip PK, He YY, Hsu CY, Garg N, Marangos P, Hogan EL. Effect 
of plasma glucose on infarct size in focal cerebral ischemiareperfusion. Neurology 1991;41:899-905.

91. Chopp M, Welch KM, Tidwell CD, Helpern JA. Global cerebral ischemia and intracellular $\mathrm{pH}$ during hyperglycemia and hypoglycemia in cats. Stroke 1988;19:1383-1387.

92. Lin B, Busto R, Globus MY, Martinez E, Ginsberg MD. Brain temperature modulations during global ischemia fail to influence extracellular lactate levels in rats. Stroke 1995;26: 1634-1638.

93. Park WS, Chang YS, Lee M. Effects of hyperglycemia or hypoglycemia on brain cell membrane function and energy metabolism during the immediate reoxygenation-reperfusion period after acute transient global hypoxia-ischemia in the newborn piglet. Brain Res 2001;901:102-108.

94. Tsuruta R, Fujita M, Ono T, Koda Y, Koga Y, Yamamoto T, et al. Hyperglycemia enhances excessive superoxide anion radical generation, oxidative stress, early inflammation, and endothelial injury in forebrain ischemia/reperfusion rats. Brain Res 2010;1309:155-163.

95. Allen $\mathrm{CL}$, Bayraktutan U. Antioxidants attenuate hyperglycaemia-mediated brain endothelial cell dysfunction and blood-brain barrier hyperpermeability. Diabetes Obes Metab 2009;11:480-490.

96. Suh SW, Shin BS, Ma H, Van Hoecke M, Brennan AM, Yenari $M A$, et al. Glucose and NADPH oxidase drive neuronal superoxide formation in stroke. Ann Neurol 2008;64:654-663.

97. Ling PR, Smith RJ, Bistrian BR. Hyperglycemia enhances the cytokine production and oxidative responses to a low but not high dose of endotoxin in rats. Crit Care Med 2005;33: 1084-1089.

98. Pérez-Asensio FJ, de la Rosa $X_{1}$ Jiménez-Altayó $F$, Gorina $R_{1}$ Martínez $E_{1}$ Messeguer $A$, et al. Antioxidant CR- 6 protects against reperfusion injury after a transient episode of focal brain ischemia in rats. J Cereb Blood Flow Metab 2010;30: 638-652.

99. Sutherland BA, Minnerup J, Balami JS, Arba F, Buchan AM, Kleinschnitz C. Neuroprotection for ischaemic stroke: translation from the bench to the bedside. Int J Stroke 2012;7: 407-418.

100. Dikalova AE, Bikineyeva AT, Budzyn K, Nazarewicz RR, McCann $\mathrm{L}$, Lewis $\mathrm{W}$, et al. Therapeutic targeting of mitochondrial superoxide in hypertension. Circ Res 2010;107:106-116.

101. Sumimoto H. Structure, regulation and evolution of Noxfamily NADPH oxidases that produce reactive oxygen species. FEBS J 2008;275:3249-3277.

102. Abramov AY, Scorziello A, Duchen MR. Three distinct mechanisms generate oxygen free radicals in neurons and contribute to cell death during anoxia and reoxygenation. J Neuro- sci 2007;27:1129-1138.

103. Kahles T, Luedike P, Endres $M$, Galla HJ, Steinmetz $H$, Busse $R$, et al. NADPH oxidase plays a central role in blood-brain barrier damage in experimental stroke. Stroke 2007;38:3000-3006.

104. Green SP, Cairns B, Rae J, Errett-Baroncini C, Hongo JA, Erickson RW, et al. Induction of gp91-phox, a component of the phagocyte NADPH oxidase, in microglial cells during central nervous system inflammation. J Cereb Blood Flow Metab 2001;21:374-384.

105. Kahles T, Brandes RP. Which NADPH oxidase isoform is relevant for ischemic stroke? The case for Nox 2. Antioxid Redox Signal 2013;18:1400-1417.

106. Kleinschnitz $C$, Grund $H$, Wingler $K$, Armitage ME, Jones $E_{1}$ Mittal $M$, et al. Post-stroke inhibition of induced NADPH oxidase type 4 prevents oxidative stress and neurodegeneration. PLoS Biol 2010;8:e1000479.

107. Jackman KA, Miller AA, De Silva TM, Crack PJ, Drummond GR, Sobey CG. Reduction of cerebral infarct volume by apocynin requires pretreatment and is absent in Nox2-deficient mice. Br J Pharmacol 2009;156:680-688.

108. Arimura K, Ago T, Kuroda J, Ishitsuka K, Nishimura A, Sugi-

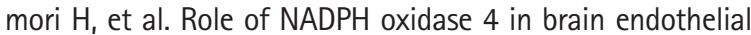
cells after Ischemic stroke. Stroke 2012;43:A2514.

109. Nagel S, Hadley G, Pfleger K, Grond-Ginsbach C, Buchan AM, Wagner $S$, et al. Suppression of the inflammatory response by diphenyleneiodonium after transient focal cerebral ischemia. J Neurochem 2012;123 Suppl 2:98-107.

110. Wind $S$, Beuerlein $K$, Eucker $T$, Müller $H$, Scheurer $P$, Armitage $M E_{1}$ et al. Comparative pharmacology of chemically distinct NADPH oxidase inhibitors. Br J Pharmacol 2010;161:885-898.

111. Wassmann S, Laufs U, Müller K, Konkol C, Ahlbory K, Bäumer $A T$, et al. Cellular antioxidant effects of atorvastatin in vitro and in vivo. Arterioscler Thromb Vasc Biol 2002;22:300-305.

112. Willmot M, Gray L, Gibson C, Murphy S, Bath PM. A systematic review of nitric oxide donors and L-arginine in experimental stroke; effects on infarct size and cerebral blood flow. Nitric Oxide 2005;12:141-149.

113. Harston GW, Sutherland BA, Kennedy J, Buchan AM. The contribution of L-arginine to the neurotoxicity of recombinant tissue plasminogen activator following cerebral ischemia: a review of rtPA neurotoxicity. J Cereb Blood Flow Metab 2010;30:1804-1816.

114. Lapchak PA, Daley JT, Boitano PD. A blinded, randomized study of L-arginine in small clot embolized rabbits. Exp Neurol 2015;266:143-146.

115. Hardingham GE, Lipton SA. Regulation of neuronal oxidative and nitrosative stress by endogenous protective pathways and disease processes. Antioxid Redox Signal 2011;14:1421-1424. 
116. Xu Z, Cho H, Hartsock MJ, Mitchell KL, Gong J, Wu L, et al. Neuroprotective role of Nrf2 for retinal ganglion cells in ischemia-reperfusion. J Neurochem 2015;133:233-241.

117. Chen XM, Chen HS, Xu MJ, Shen JG. Targeting reactive nitrogen species: a promising therapeutic strategy for cerebral ischemia-reperfusion injury. Acta Pharmacol Sin 2013;34:67-77.

118. Wong CH, Bozinovski S, Hertzog PJ, Hickey MJ, Crack PJ. Absence of glutathione peroxidase- 1 exacerbates cerebral ischemia-reperfusion injury by reducing post-ischemic microvascular perfusion. J Neurochem 2008;107:241-252.

119. Bell KF, Hardingham GE. CNS peroxiredoxins and their regulation in health and disease. Antioxid Redox Signal 2011;14: 1467-1477.

120. Szabó C, Ischiropoulos H, Radi R. Peroxynitrite: biochemistry, pathophysiology and development of therapeutics. Nat Rev Drug Discov 2007;6:662-680.

121. Suofu Y, Clark J, Broderick J, Wagner KR, Tomsick T, Sa Y, et al. Peroxynitrite decomposition catalyst prevents matrix metalloproteinase activation and neurovascular injury after prolonged cerebral ischemia in rats. J Neurochem 2010;115: 1266-1276.

122. Palomares SM, Gardner-Morse I, Sweet JG, Cipolla MJ. Peroxynitrite decomposition with FeTMPyP improves plasma-induced vascular dysfunction and infarction during mild but not severe hyperglycemic stroke. J Cereb Blood Flow Metab 2012;32:1035-1045.

123. Mackensen GB, Patel M, Sheng $H$, Calvi CL, Batinic-Haberle I, Day BJ, et al. Neuroprotection from delayed postischemic administration of a metalloporphyrin catalytic antioxidant. $J$ Neurosci 2001;21:4582-4592.

124. Sheng H, Enghild JJ, Bowler R, Patel M, Batinić-Haberle I, Calvi $\mathrm{CL}$, et al. Effects of metalloporphyrin catalytic antioxidants in experimental brain ischemia. Free Radic Biol Med 2002;33:947-961. 